\title{
Adsorptive Stripping Voltammetric Determination of Mangiferin Using an Activated Chitosan Modified Carbon Paste Electrode
}

\author{
Francis Merlin Melataguia Tchieno', Evangeline Njanja1, Léon Azefack Tapondjou2, \\ Ignas Kenfack Tonle ${ }^{1^{*}}$ \\ ${ }^{1}$ Electrochemistry and Chemistry of Materials, Department of Chemistry, University of Dschang, Dschang, \\ Cameroon \\ ${ }^{2}$ Laboratory of Applied and Environmental Chemistry, Department of Chemistry, University of Dschang, \\ Dschang, Cameroon \\ Email: itonle@yahoo.com
}

Received 7 April 2014; revised 13 May 2014; accepted 20 May 2014

Copyright (C) 2014 by authors and Scientific Research Publishing Inc.

This work is licensed under the Creative Commons Attribution International License (CC BY).

http://creativecommons.org/licenses/by/4.0/

(c) (i) Open Access

\begin{abstract}
A medium molecular weight powdered chitosan modified carbon paste electrode was used to investigate the electrochemical behaviour by cyclic voltammetry of the pharmacologically-active ingredient mangiferin (MG). An irreversible system was observed, with a peak at +0.55 V (vs $\mathrm{Ag} / \mathrm{AgCl}$ ). The peak current increases about fourfold, at the modified electrode in comparison with that recorded at the chitosan free carbon paste electrode. This allowed the use of adsorptive stripping voltammetry to develop a simple and sensitive electroanalytical method for the determination of MG. The influence of key parameters was investigated, including the electrolysis potential, the preconcentration time, the pH of supporting electrolyte and MG concentration. Upon optimisation of these parameters, the electrode response was found to be directly proportional to the concentration of MG in the range from $2.06 \times 10^{-6} \mathrm{M}$ to $6.74 \times 10^{-5} \mathrm{M}$, leading to a detection limit of $1.84 \mu \mathrm{M}$ for $240 \mathrm{~s}$ preconcentration at $-0.1 \mathrm{~V}$. A mechanism was also proposed for the electrochemical oxidation of MG.
\end{abstract}

\section{Keywords}

Mangiferin (Mangifera indica L.), Xanthones, Carbon Paste Electrode, Chitosan, Stripping Voltammetry

\footnotetext{
${ }^{*}$ Corresponding author.
}

How to cite this paper: Tchieno, F.M.M., et al. (2014) Adsorptive Stripping Voltammetric Determination of Mangiferin Using an Activated Chitosan Modified Carbon Paste Electrode. American Journal of Analytical Chemistry, 5, 424-432. 


\section{Introduction}

The drug industry is experiencing a boom as a consequence of the advances in ethnopharmacology [1]. The identification, description and experimental investigation of the ingredients of indigenous drugs are becoming more important owing to the need to understand their therapeutic and toxic effects [1] [2]. One of such ingredients that have undergone close scrutiny in recent years is mangiferin (MG), a C-glucosylxanthone (Scheme 1). MG belongs to the class of yellow oxygenated heterocyclics called xanthones, whose role is well-known in medicinal chemistry [3] [4]. The extraction of this promising pharmacological ingredient from various parts of the tropical based Mangifera indica L. by different authors has been reviewed by [5]. One could also mention a related work by [6] who comprehensively reviewed literature data on phytochemical and pharmacological investigations conducted on MG. In fact, this product displays numerous therapeutic and bioactive activities. It has been shown to be among others an antiallergic and antioxidant [7], antidiabetic [8], antiviral [9], antitumoral and anti-HIV [10] molecule. To date, huge data are available which are focused on extraction, isolation and purification techniques leading to MG from leaves, fruits, roots and heartwood of Mangifera indica L. These techniques include mostly mass spectrometry [11], nuclear magnetic resonance [12] [13], microextraction [14]-[16] and chromatographic methods [17]-[19].

On the other hand, it is quite well-known that the quantification of bioactive molecules in body fluids can improve pharmacotherapy and patient care [20]. This aspect appears to be of key importance since biological matrices are often complex due to the presence of coexisting components, with chemical properties similar to those of the target analyte. In addition, sample pretreatment is usually necessary, and in most cases the analyte of interest is present at low concentrations. Therefore, the monitoring and the measurement of concentrations of drugs in biological media remain a daily and challenging question in both medicinal chemistry and analytical science. Following these lines, the development of methods based on electrochemical sensors is of great interest in biomedical analysis. Electrochemical procedures are increasingly under investigation and could advantageously serve as alternatives to chromatographic and spectral methods for their miniature size, rapid analysis time and low cost [21] [22]. Moreover, they can give rise to excellent sensitivity with a large useful concentration range for both inorganic and organic species [23]. Of great interest in this area are devices based on modified electrodes which can be easily designed for the sensitive and selective detection of a given analyte. Specifically, chemically modified carbon paste electrodes (CMCPEs) have been largely investigated and proved to be versatile tools for the detection of electroactive compounds. The continuing resort to these electrodes resides in their flexibility, as they can be conveniently modified by a compound and/or a material displaying a great affinity towards a precise analyte. Typical works dealing with the electroanalysis of organic and biologically important molecules using CMCPEs were reported [24]-[26]. Thus, the simultaneous determination of rutin and quercetin (flavonoids and antioxydants) was achieved at a multi-walled carbon nanotube paste electrode by reversing differential pulse voltammetry [27]. Similarly, using nanotube modified carbon paste electrodes, some pharmaceuticals were successfully determined which include oxytetracycline [28], urapidyl [29], piroxicam [30], and isoniazid [31]. One could also mention some relevant works where the analytical performance of such electrodes towards the electrocatalytic properties of biomolecules involving important enzymatic processes has been demonstrated [32]-[34]. A review covering the exploitation of electrochemical tools for the determination of phenolic and MG-like compounds was released recently by [35]. However, to the best of our knowledge, no electroanalytical investigation has been reported for the quantification of MG using a CMCPE. In the present study, the electrochemical oxidation mechanism of MG was first investigated by cyclic voltammetry. Using differential pulse voltammetry, a quite simple and sensitive method was developed for its quantitative detection in aqueous buffer solution, by a powdered chitosan carbon paste composite electrode.

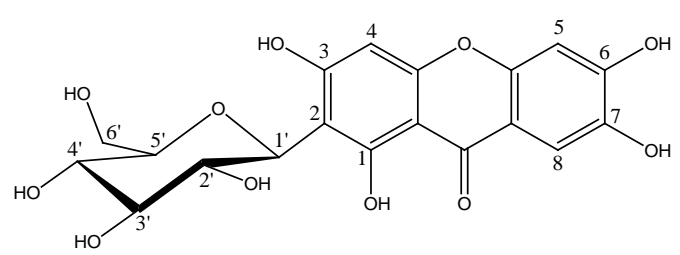

Scheme 1. Molecular structure of mangiferin. 
Chitosan was chosen as efficient modifier for organophilic character and porous morphology that were previously reported to favour the accumulation of phenolic compounds at nanoparticles modified carbon paste electrodes [36]-[38].

\section{Experimental}

\subsection{Reagents and Chemicals}

The MG sample used was extracted from Bersama engleriana stem bark following a procedure previously described [39]. Prior to use, a stock solution of MG $\left(1.04 \times 10^{-3} \mathrm{M}\right)$ was prepared in $\mathrm{MeOH}$ and then diluted to the desired concentrations by mixing with supporting electrolyte. The MG stock solution was stored at room temperature (about $23^{\circ} \mathrm{C}$ ). Buffer supporting electrolyte solutions were prepared by mixing either solutions of $\mathrm{KH}_{2} \mathrm{PO}_{4}$ and $\mathrm{Na}_{2} \mathrm{HPO}_{4}$ (both from $\mathrm{BDH}$ ), $\mathrm{HCl}$ and $\mathrm{KCl}$ (from Fischer scientific international) or $\mathrm{CH}_{3} \mathrm{COOH}$ and $\mathrm{CH}_{3} \mathrm{COONa}$ from Fischer scientific international and BDH respectively. The buffer solutions were used immediately after preparation. The $\mathrm{pH}$ of buffer solutions was adjusted with molar basic or acidic solutions prepared from pellets of $\mathrm{NaOH}$ (Prolabo) and commercial $\mathrm{HCl}$ solution. The medium molecular weight chitosan $\left(\mathrm{C}_{12} \mathrm{H}_{24} \mathrm{~N}_{2} \mathrm{O}_{9}\right)$ was purchased from Sigma-Aldrich. Ascorbic acid was purchased from Aldrich, uric acid from BDH-Prolabo, dopamine hydrochloride and D-(+)-glucose from Sigma-Aldrich, L-aspartic acid from Fischer Scientific International and citric acid monohydrate from J.T. Baker. Ascorbic acid, dopamine, L-aspartic acid, citric acid and D-(+)-glucose solutions were prepared in water while uric acid solutions were prepared in $\mathrm{NaOH}$ solutions, and used immediately thereafter. The human urine sample was collected from healthy laboratory staff, diluted 300 times with supporting electrolyte solution and used immediately thereafter.

\subsection{Apparatus}

Electrochemical measurements were carried out using a $\mu$-Autolab potentiostat-galvanostat (type III) running with GPES software, supplied by EcoChemie, Utrecht (The Netherlands). A standard single compartment three electrode cell was used. Electrode potentials were measured with respect to an $\mathrm{Ag} / \mathrm{AgCl} / 3 \mathrm{M} \mathrm{KCl}$ reference electrode (Metrohm, Ref 6.0726.100); a stainless steel rod was used as counter electrode. The working electrode was a chitosan modified carbon paste electrode prepared as described below. Electrochemical experiments were carried out without degassing the supporting electrolyte solution.

\subsection{Preparation of the Chitosan/Carbon Paste Composite Electrode}

The chitosan/carbon paste (100 mg) was made up of 67\% graphite powder (Alfa), 3\% chitosan powder and 30\% silicone oil (Aldrich). The three components were mechanically mixed to obtain a homogenous paste. This paste was then firmly packed into the cavity ( $2.5 \mathrm{~mm}$ inner diameter) of a teflon tube and through which moves a screwed stainless steel rod. The electrode obtained is hereafter designated CPE-CHI (3\%).

\subsection{Electroanalytical Procedures}

The modified electrode's active surface area was electrically activated by immersion in $0.5 \mathrm{M} \mathrm{HCl}$ solution, followed by five cyclic voltammetric scans from $-0.2 \mathrm{~V}$ to $+1 \mathrm{~V}$. This electrical activation led to the protonation of the amino $\left(-\mathrm{NH}_{2}\right)$ groups of chitosan to form $-\mathrm{NH}_{3}^{+}$groups [40]. Cyclic voltammograms were recorded by transferring the chitosan-CPE either in a phosphate buffer (PB), $\mathrm{HCl} / \mathrm{KCl}$ or in an acetate buffer $(\mathrm{AB})$ solution containing MG at a given concentration. The potential scan rate was $75 \mathrm{mV} \cdot \mathrm{s}^{-1}$ and the scanning was performed from $-0.2 \mathrm{~V}$ to $+1 \mathrm{~V}$. MG stripping analysis was carried out following a 2 step procedure: 1 ) a preconcentration step at open-circuit, during which the working electrode was immersed for a defined period of time in an aqueous solution of MG under mild mechanical stirring; 2) a detection step where the electrode was rapidly removed from the preconcentration solution, rapidly rinsed with double distilled water and transferred to the buffer detection solution in the electrochemical cell. The electrode response was immediately recorded using differential pulse voltammetry (DPV) with the following conditions: pulse amplitude $50 \mathrm{mV}$, step potential $5 \mathrm{mV}$, initial potential $+0.2 \mathrm{~V}$, final potential $+0.8 \mathrm{~V}$ and equilibrium time $5 \mathrm{~s}$. Electrolysis potential and accumulation time were optimised. Prior to each measurement, the electrode surface was renewed by polishing with a soft and smooth piece of paper. 


\section{Results and Discussion}

\subsection{Preliminary Investigations}

Some preliminary studies were undertaken to evaluate the contribution of chitosan modification towards the electrochemical signal of MG. Figure 1 compares the cyclic voltammograms recorded in $0.1 \mathrm{M} \mathrm{PB}$ (pH 5) using a bare CPE and an activated CPE-CHI (3\%). The oxidation of MG occurred at $+0.55 \mathrm{~V}$, giving rise to a peak with intensity more than 4 times greater at the chitosan modified electrode in comparison with the bare CPE.

This enhancement could be reasonably explained by electrostatic interactions between the $-\mathrm{NH}_{3}{ }^{+}$groups on the protonated chitosan and lone pairs of electrons on the -OH groups of MG. Since the current response is shown to be dependent on chitosan, the amount of the later was varied within the CPE from $1 \%$ to $10 \%$ by mass: the highest peak current was obtained when the proportion of chitosan in the paste was equal to $3 \%$. Such an electrode was used throughout the work and is referred to as CPE-CHI (3\%).

It is noteworthy to mention here that the activation of chitosan-modified CPEs was achieved in $0.5 \mathrm{M} \mathrm{HCl}$ solution, but performing electrochemical experiments in the same medium lead to the electrode surface collapse as a consequence of a stronger protonation of chitosan which render the paste less stable. Thus, buffer solutions were used as supporting electrolyte for investigations.

\subsection{Optimisation of Experimental Conditions for Analytical Application}

In order to establish an electroanalytical method for the quantitative determination of MG, differential pulse voltammetry, one of the most sensitive electrochemical techniques was further exploited in adsorptive mode.

The feasibility of the two step procedures described in the experimental section was beforehand checked for the analysis of MG by recording in $0.1 \mathrm{M} \mathrm{PB}(\mathrm{pH}$ ) the response of CPE-CHI (3\%) after 4 minutes preconcentration in an aqueous solution of $1.03 \times 10^{-5} \mathrm{M} \mathrm{MG}$. A well defined anodic peak was then obtained at $+0.43 \mathrm{~V}$, with a current of $7 \mu \mathrm{A}$. In comparison with the experiment described in Figure 1, this revealed the sensitivity of the chitosan modified electrode when exploited through adsorptive stripping voltammetry.

The key parameters likely to influence the analytical performance of the sensor proposed herein were then evaluated. These include the immersion time of the electrode in MG solution (preconcentration step), the electrolysis potential, the $\mathrm{pH}$ of the supporting electrolyte and MG concentration in the preconcentration medium.

As shown on Figure 2(a), the oxidation peak current of MG increased remarkably with accumulation time from $0 \mathrm{~s}$ to $240 \mathrm{~s}$, and then reached a plateau. This fact probably indicates that the adsorptive equilibrium was reached after 4 minutes accumulation. A preconcentration time of 4 minutes was therefore taken as optimum accumulation time and used in subsequent analyses. The evolution of peak current as a function of electrolysis potential is shown on Figure 2(b). The peak intensity increased with electrolysis potential from $-0.6 \mathrm{~V}$ to attain a maximum at $-0.1 \mathrm{~V}$, then dropped beyond this value which was taken as the best compromise for the electrolysis of MG at CPE-CHI (3\%).

MG is an organic molecule with hydroxyl and catechol-like groups in its structure, and the redox behaviour of such a compound is expected to involve protons. Figure 3(a) presents the evolution of the anodic stripping voltammograms of MG when the $\mathrm{pH}$ of buffer solutions used as detection media was varied from 1 to 6 . The oxidation peak potential $\left(\mathrm{E}_{\mathrm{p}}\right)$ of $\mathrm{MG}$ was found to shift negatively with the increase of $\mathrm{pH}$. A good linear relationship was observed between $\mathrm{E}_{\mathrm{p}}$ and the $\mathrm{pH}$ (Figure 3(b)), with the equation $\mathrm{E}_{\mathrm{p}}=-0.0618 \mathrm{pH}+0.7577(\mathrm{R}=$ 0.9978 ). A value of $-0.0618 \mathrm{~V}$ per $\mathrm{pH}$ unit is close to the theoretical Nernstian value of $-0.059 \mathrm{~V}$ [41] and indicated that equal number of electrons and protons are involved in the electrooxidation of MG. At $\mathrm{pH} \geq 8$, MG is easily and rapidly oxidised by the dissolved oxygen in the solution and a green coloration probably of the quinonic form appears. No peak was obtained for this solution. It is therefore recommended, as for all hydroquinone-like compounds in the presence of oxygen to work at $\mathrm{pH} \leq 8$.

Using the previous optimised parameters, increasing the concentration of MG in the supporting electrolyte in the range from $2.06 \times 10^{-6} \mathrm{M}$ to $6.74 \times 10^{-5} \mathrm{M}$ led to the curve in Figure 4(a). The results obtained revealed a linear relationship between $M G$ concentration $\left(C_{M G}\right)$ and peak current $\left(I_{p}\right)$, with the following equation: $I_{p}(\mu A)$ $=0.676 \mathrm{C}_{\mathrm{MG}}(\mu \mathrm{M})-1.524$. A correlation coefficient of 0.997 was obtained for the calibration graph, thus indicating a good linearity between peak current and MG concentration. For the elaborated analytical method, the limit of detection defined as $3 \mathrm{~s} / \mathrm{m}$ (where $\mathrm{s}$ is the blank standard deviation $(\mathrm{N}=16)$ and $\mathrm{m}$ the slope of the calibration curve) was calculated and found to be $1.84 \mu \mathrm{M}$ MG. For practical analysis, the developed analytical 


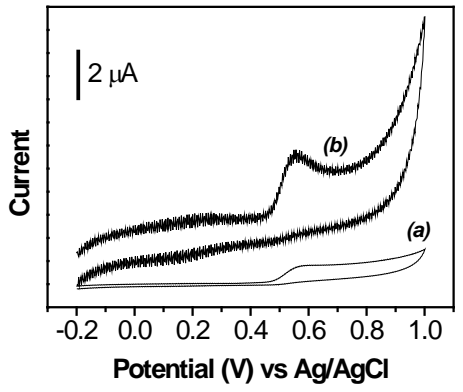

Figure 1. Cyclic voltammetric response of $2.04 \times 10^{-5} \mathrm{M}$ MG in PB (pH 5) on (a) bare CPE and (b) activated CPE-CHI (3\%). Potential scanrate $75 \mathrm{~m} \cdot \mathrm{Vs}^{-1}$.
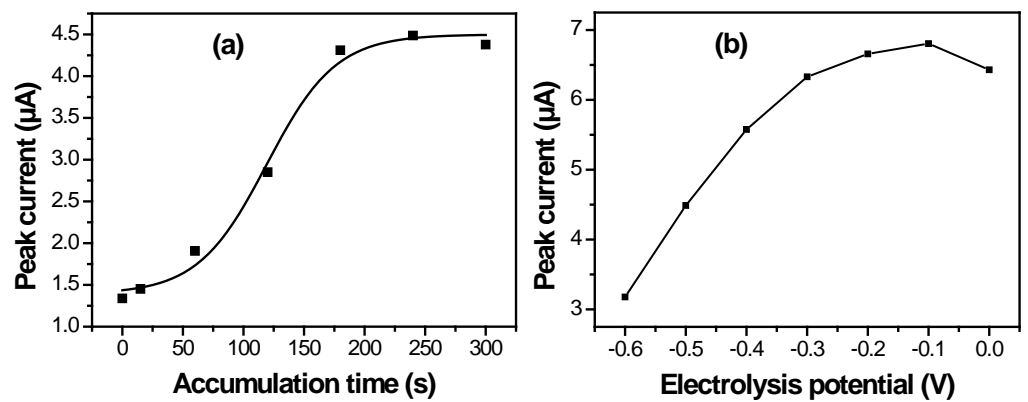

Figure 2. Dependence of current reponse at CPE-CHI (3\%) for $1.03 \times 10^{-5} \mathrm{M}$ MG in $0.1 \mathrm{M} \mathrm{PB}$ ( $\mathrm{pH}$ 5) on (a) accumulation time and (b) electrolysis potential.

method was applied to the quantification of MG in human urine. The urine sample was collected, diluted 300 times with $\mathrm{HCl} / \mathrm{KCl}$ buffer to reduce interferences and MG of different concentrations added. In the absence of MG, a current of about $5.03 \mu \mathrm{A}$ was measured. This was principally due to the presence of uric acid in the human urine sample. Upon successive addition of MG, the latter value was subtracted from the current responses and the currents due to the addition of MG alone are represented in Figure 4(b) against concentration. In this biological medium, a linear relation was obtained between peak current and MG concentration in the range 2.04 $\times 10^{-6} \mathrm{M}$ to $5.95 \times 10^{-5} \mathrm{M}$ with a correlation coefficient of 0.996 . The calibration equation was $\mathrm{I}_{\mathrm{p}}(\mu \mathrm{A})=0.325$ $\mathrm{C}_{\mathrm{MG}}(\mu \mathrm{M})+0.308$ and a limit of detection $(3 \mathrm{~s} / \mathrm{m})$ of $2.98 \mu \mathrm{M}$ was calculated for MG quantification in the presence of human urine.

To test the accuracy of the developed method and of the calibration equation, recovery experiments were carried out. An average percent recovery of $96.70 \%$ was found. A relative standard deviation of $4.10 \%(\mathrm{~N}=4)$ was calculated, which is indicative of a good reproducibility of measurements. To validate the proposed MG analysis method, the influence of six potential compounds that usually coexist in biological media, namely uric acid (UA), ascorbic acid (AA), dopamine (DA), L-aspartic acid (AsA), citric acid (CA) and D-(+)-glucose, was evaluated. As shown in Table 1, all the species interfered with MG signal: their oxidation occurred at almost the same potential, and their presence increased or decreased the signal of MG. It was noted that for the same concentration, DA interfered most with the oxidation peak of MG while CA and AsA interfered least.

\subsection{Electrochemical Oxidation Mechanism of Mangiferin}

This work reported the first electrochemical investigation of MG, and we were interested in the mechanism involved in its electrochemical behavior. To better understand the electrochemical oxidation mechanism of MG, its electrochemical behavior was compared to that of compounds with similar moieties to those present in MG. The dependence of the oxidation peak potential of MG on $\mathrm{pH}$ (Figure 3(b)) indicates that protons are involved in the oxidation mechanism [42]. The slope of this graph $(-0.0618 \mathrm{~V}$ per $\mathrm{pH}$ unit) equally indicated a mechanism with equal number of protons and electrons [41]. At $\mathrm{pH} \geq 8$, a chemical reaction took place upon addition of MG to the supporting electrolyte. This is typical hydroquinonic behaviour at $\mathrm{pH} \geq 8$. Previous studies report hydroquinonic and catechol-like oxidations as 2 electrons and 2 protons transfer processes at electrode surface in 
acidic media [43]-[46]. Both electrons and protons are therefore removed from the MG molecule during oxidation to produce a stable electroinactive quinonic form. Based on the above, we proposed the mechanism shown in Scheme 2 for the electrochemical oxidation of MG.

\section{Conclusion}

In this work, a simple method was developped for the quantitative determination of mangiferin, a compound of
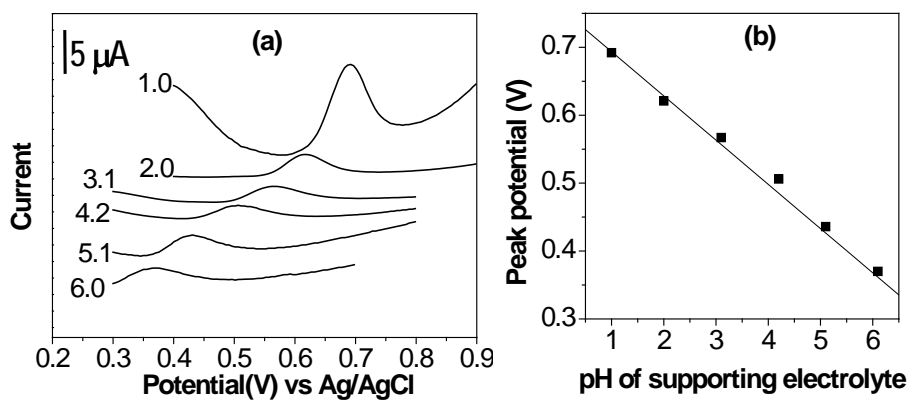

Figure 3. (a) Effect of detection medium $\mathrm{pH}$ on the anodic peak current of MG, at $\mathrm{CPE}-\mathrm{CHI}$ (3\%). (b) Variation of the peak potential as a function of $\mathrm{pH}$ of the detection medium.
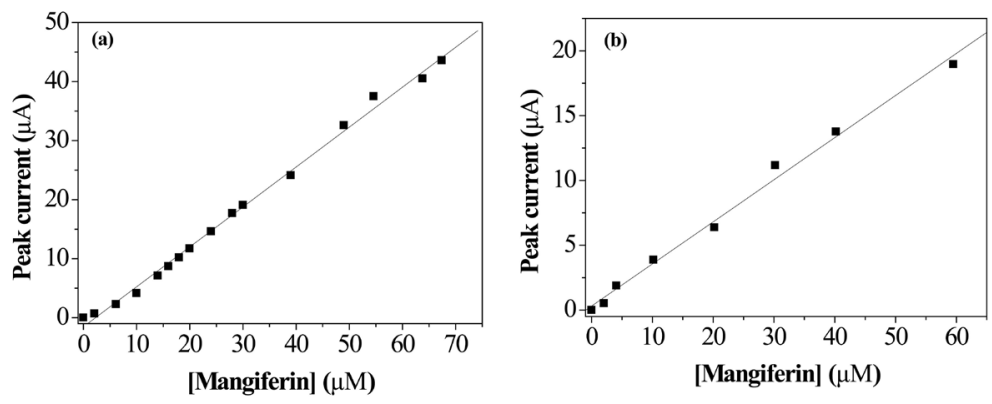

Figure 4. (a) Calibration graph of MG obtained on CPE-CHI (3\%) in $\mathrm{HCl} / \mathrm{KCl}$ buffer solution (pH 1) under optimised conditions: $0,0.206,0.614,1.0,1.4,1.6,1.8,2.0,2.4,2.8,3.0,3.96,4.9,5.46$, 6.38, $6.74 \times 10^{-5} \mathrm{M}$ MG. (b) Calibration graph of MG obtained on CPE-CHI (3\%) in $\mathrm{HCl} / \mathrm{KCl}$ buffer (pH 1)/human urine mixture: $0,2.04,4.08,10.2,20.2,30.2,40.2,59.5 \mu \mathrm{M} \mathrm{MG}$.<smiles>[CH]c1c(O)cc2oc3cc(O)c(C)c(O)c3c(=O)c2c1O</smiles>

Scheme 2. Proposed electrochemical oxidation mechanism of mangiferin.

Table 1. Influence of some organic compounds on the determination of $1.01 \times 10^{-5} \mathrm{M}$ MG.

\begin{tabular}{ccc}
\hline Interfering organic species & Concentration $(\mu \mathrm{M})$ & Increase in peak current of $\mathrm{MG}$ \\
\hline Ascorbic acid & 51.1 & $\approx 19 \%$ \\
Uric acid & 51.1 & $\approx 30 \%$ \\
Dopamine & 51.1 & $\approx 63 \%$ \\
L-aspartic acid & 51.1 & $\approx-2 \%$ \\
Citric acid & 51.1 & $\approx 1 \%$ \\
D-(+)-glucose & 51.1 & $\approx 18 \%$ \\
\hline
\end{tabular}


great interest because of its potential benefits in medicine. This new study reveals that the electrochemical oxidation of mangiferin is an irreversible, two-electron two-proton transfer and $\mathrm{pH}$ dependent process. The oxidation product of mangiferin adhered at the electrode surface, resulting in a decrease of peak currents in successive scans. The medium exchange method reduces the effect of interfering electroactive species such as ascorbic acid and uric acid. Discrimination of the signals of mangiferin, ascorbic acid and uric acid is an ongoing project. The deprotonation of hydroxyl groups in the course of the electrochemical oxidation of mangiferin confirms the fact that its radical scavenging (antioxidant) activity, as well as that of other polyphenols, is related to its electron/ proton donating capacity.

\section{Acknowledgements}

The financial support from the Academy of Science for the Developing World (Grant No. 12-117 RG/CHE/AF/ AC-G; UNESCO FR: 12-117 RG/CHE/AF/AC-G) is gratefully acknowledged.

\section{References}

[1] Freitas, P.G., Barbosa. A.F., Saraiva, L.A., Camps, I., Da Silveira, N.J.F., Veloso, M.P., Santos, M.H. and Schneedorf, J.M. (2012) Mangiferin Binding to Serum Albumin Is Non-Saturable and Induces Conformational Changes at High Concentrations. Journal of Luminescence, 132, 3027-3034. http://dx.doi.org/10.1016/j.jlumin.2012.06.020

[2] Hiroyuki, K. (2010) Recent Developments and Applications of Microextraction Techniques in Drug Analysis. Analytical and Bioanalytical Chemistry, 396, 339-364. http://dx.doi.org/10.1007/s00216-009-3076-2

[3] Geodakyan, S.V., Voskoboinikova, I.V., Tjukavkina, N.A., Kolhir, V.K., Kolesnik, Y.A., Zjuzin, V.A., Glyzin, V.I. and Sokolov, S.J. (2006) Experimental Pharmacokinetics of Biologically Active Plant Phenolic Compounds. I. Pharmacokinetics of Mangiferin in the Rat. Phytotherapy Research, 6, 332-334. http://dx.doi.org/10.1002/ptr.2650060611

[4] Luo, F., Lv, Q., Zhao, Y., Hu, G., Huang, G., Zhang, J., Sun, C., Li, X. and Chen, K. (2012) Quantification and Purification of Mangiferin from Chinese Mango (Mangifera indica L.) Cultivars and Its Protective Effect on Human Umbilical Vein Endothelial Cells under $\mathrm{H}_{2} \mathrm{O}_{2}$-Induced Stress. International Journal of Molecular Sciences, 13, 11260-11274. http://dx.doi.org/10.3390/ijms130911260

[5] Wauthoz, N., Balde, A., Balde, E.S., Van Damme, M. and Duez, P. (2007) Ethnopharmacology of Mangifera indica L. Bark and Pharmacological Studies of Its Main C-Glucosylxanthone, Mangiferin. International Journal of Biomedical and Pharmaceutical Sciences, 1, 112-119.

[6] Singh, K.S., Sharma, V.K., Kumar, Y., Kumar, S.S. and Sinha, S.K. (2009) Phytochemical and Pharmacological Investigations on Mangiferin. Herba Polonica, 55, 126-139.

[7] Pardo-Andreu, G.I., Delgado, R., Nunez-Selles, A.J. and Vercesi, A.F. (2006) Mangifera indica L. Extract (Vimang®) Inhibits 2-Deoxyribose Damage Induced by Fe(III) plus Ascorbate. Phytotherapy Research, 20, 120-124.

http://dx.doi.org/10.1002/ptr.1813

[8] Aderigbe, A.O., Emudianughe, T.S. and Lowal, B.A. (2001) Evaluation of the Antidiabetic Action of Mangifera indica in Mice. Phytotherapy Research, 15, 456-458. http://dx.doi.org/10.1002/ptr.859

[9] Mancini, D.A.P., Torres, R.P., Pinto, J.R. and Mancini-Filho, J. (2009) Inhibition of DNA Virus: Herpes-1 (HSV-1) in Cellular Culture Replication, through an Antioxidant Treatment Extracted from Rosemary Spice. Journal of Pharmaceutical Sciences, 45, 127-131.

[10] Guha, S., Ghosal, S. and Chattopadyay, U. (1996) Antitumor, Immunomodulatory and Anti-HIV Effect of Mangiferin, a Naturally Occurring Glucosylxanthone. Chemotherapy, 42, 443-451. http://dx.doi.org/10.1159/000239478

[11] Ghosal, S. and Chaudary, R.K. (1971) Xanthones of Canscora decussata Schult. Phytochemistry, 10, 2425-2432. http://dx.doi.org/10.1016/S0031-9422(00)89890-8

[12] Rojas-Hernandez, A., Gomez-Zaleta, B., Ramirez-Silva, M.T., Gutierrez, A., Gonzalez-Vergara, E. and Guizado-Rodriguez, M. (2006) UV/Vis, ${ }^{1} \mathrm{H}$, and ${ }^{13} \mathrm{C}$ NMR Spectroscopic Studies to Determine Mangiferin pK(a) Values. Spectrochimica Acta A, 64, 1002-1009. http://dx.doi.org/10.1016/j.saa.2005.09.009

[13] Frahm, A.W. and Chaudhuri, R.K. (1979) ${ }^{13}$ C NMR Spectroscopy of Substituted Xanthones-II: ${ }^{13}$ C NMR Spectral Study of Polyhydroxy Xanthones. Tetrahedron, 35, 2035-2038. http://dx.doi.org/10.1016/S0040-4020(01)88974-2

[14] Bhatia, V.K., Ramanathan, J.D. and Seshadri, T.R. (1967) Constitution of Mangiferin. Tetrahedron, 23, $1363-1368$. http://dx.doi.org/10.1016/0040-4020(67)85090-7

[15] Saleh, N.A.M. and El Ansari, M.A.I. (1975) Polyphenolics of Twenty Local Varieties of Mangifera indica. Planta Medica, 28, 124-130. http://dx.doi.org/10.1055/s-0028-1097840

[16] Tanaka, T., Sueyasu, T., Nonaka, G. and Nishioka, I. (1984) Tannins and Related Compounds. Isolation and Characte- 
rization of Galloyl and p-Hydroxybenzoyl Ester of Benzophenone and Xanthone C-Glucosides from Mangifera indica. Chemical and Pharmaceutical Bulletin, 32, 2676-2686. http://dx.doi.org/10.1248/cpb.32.2676

[17] El Ansari, M.A., Rajadurai, S. and Nayudamma, Y. (1967) Studies on the Polyphenols of Mangifera indica Bark. Leather Science, 14, 247-251.

[18] Schrieber, A., Berardini, S. and Carle, R. (2003) Identification of Flavonol and Xanthone Glycosides from Mango (Mangifera indica L. cv. “Tommy Atkins”) Peels by High-Performance Liquid Chromatography-Electrospray Ionization Mass Spectrometry. Journal of Agricultural and Food Chemistry, 51, 5006-5011. http://dx.doi.org/10.1021/jf030218f

[19] Schrieber, A., Ullrich, W. and Carle, R. (2000) Characterization of Polyphenols in Mango Puree Concentrate by HPLC with Diode Array and Mass Spectrometric Detection. Innovative Food Science and Emerging Technologies, 1, 161166. http://dx.doi.org/10.1016/S1466-8564(00)00015-1

[20] Saint-Marcoux, F., Sauvage, F.L. and Marquet, P. (2007) Current Role of LC-MS in Therapeutic Drug Monitoring. Analytical and Bioanalytical Chemistry, 388, 1327-1349. http://dx.doi.org/10.1007/s00216-007-1320-1

[21] Wagheu, K.J., Forano, C., Besse-Hoggan, P., Tonle, I.K., Ngameni, E. and Mousty, C. (2013) Electrochemical Determination of Mesotrione at Organoclay Modified Glassy Carbon Electrodes. Talanta, 103, 337-343. http://dx.doi.org/10.1016/j.talanta.2012.10.068

[22] Kenne-Dedzo, G. and Detellier, C. (2013) Ionic Liquid-Kaolinite Nanohybrid Materials for the Amperometric Detection of Trace Levels of Iodide. Analyst, 138, 767-770. http://dx.doi.org/10.1039/c2an36618e

[23] Svancara, I., Walcarius, A., Kalcher, K. and Vytras, K. (2009) Carbon Paste Electrodes in the New Millennium. Central European Journal of Chemistry, 7, 598-656. http://dx.doi.org/10.2478/s11532-009-0097-9

[24] Nie, L.B., Gu, H.S., He, Q.G., Chen, J.R. and Miao, Y.Q. (2007) Enhanced Electrochemical Detection of DNA Hybridization with Carbon Nanotube Modified Paste Electrode. Journal of Nanoscience and Nanotechnology, 7, 560-564. http://dx.doi.org/10.1166/jnn.2007.126

[25] Luque, G.L., Ferreyra, N.F. and Rivas, A.G. (2006) Glucose Biosensor Based on the Use of a Carbon Nanotube Paste Electrode Modified with Metallic Particles. Microchimica Acta, 152, 277-283. http://dx.doi.org/10.1007/s00604-005-0447-z

[26] Shahrokhian, S., Kamalzadeh, Z., Bezaatpour, A. and Boghaei, M. (2008) Differential Pulse Voltammetric Determination of N-Acetylcysteine by the Electrocatalytic Oxidation at the Surface of Carbon Nanotube-Paste Electrode Modified with Cobalt Salophen Complexes. Sensors and Actuators B: Chemical, 133, 599-606. http://dx.doi.org/10.1016/j.snb.2008.03.034

[27] Lin, X.Q., He, J.B. and Zha, Z.G. (2006) Simultaneous Determination of Quercetin and Rutin at a Multi-Wall Carbon Nanotube Paste Electrodes by Reversing Differential Pulse Voltammetry. Sensors and Actuators B: Chemical, 119, 608-614. http://dx.doi.org/10.1016/j.snb.2006.01.016

[28] Ly, S.Y., Lee, C.H. and Jung, Y.S. (2007) Measuring Oxytetracycline Using a Simple Prepared DNA Immobilized on a Carbon Nanotube Paste Electrode in Fish Tissue. Journal of the Korean Chemical Society, 51, 412-417. http://dx.doi.org/10.5012/jkcs.2007.51.5.412

[29] Zheng, L. and Song, F.G. (2007) Voltammetric Behaviour of Urapidil and Its Determination at Multi-Wall Carbon Nanotube Paste Electrode. Talanta, 73, 943-947. http://dx.doi.org/10.1016/j.talanta.2007.05.015

[30] Abbaspour, A. and Mirzajani, R. (2007) Electrochemical Monitoring of Piroxicam in Different Pharmaceutical Forms with Multi-Walled Carbon Nanotubes Paste Electrode. Journal of Pharmaceutical and Biomedical Analysis, 44, 41-48. http://dx.doi.org/10.1016/j.jpba.2007.01.027

[31] Shahrokhian, S. and Amiri, M. (2007) Multi-Walled Carbon Nanotube Paste Electrode for Selective Voltammetric Detection of Isoniazid. Microchimica Acta, 157, 149-158. http://dx.doi.org/10.1007/s00604-006-0665-Z

[32] Rivas, A.G., Rubianes, M.D., Pedano, N.F., Ferreyra, N.F., Luque, G.L., Rodriguez, M.C. and Miscoria, S.A. (2007) Carbon Nanotubes Paste Electrodes. A New Alternative for the Development of Electrochemical Sensors. Electroanalysis, 19, 823-831. http://dx.doi.org/10.1002/elan.200603778

[33] Zou, X., Luo, L., Ding, Y. and Wu, O. (2007) Chitosan Incorporating Cetyltrimethylammonium Bromide Modified Glassy Carbon Electrode for Simultaneous Determination of Ascorbic Acid and Dopamine. Electroanalysis, 19, 18401844. http://dx.doi.org/10.1002/elan.200703945

[34] Taleat, Z., Ardakani, M.M., Naeimi, H., Beitollahi, H., Nejati, M. and Zare, H.R. (2008) Electrochemical Behavior of Ascorbic Acid at a 2,2'-[3,6-Dioxa-1,8-octanediylbis(nitriloethylidyne)]-bis-Hydroquinone Carbon Paste Electrode. Analytical Sciences, 24, 1039-1044. http://dx.doi.org/10.2116/analsci.24.1039

[35] Dobes, J., Zitka, O., Sochor, J., Ruttkay-Nedecky, B., Babula, P., Beklova, M., Kynicky, J., Hubalek, J., Klejdus, B., Kizek, R. and Adam, V. (2013) Electrochemical Tools for Determination of Phenolic Compounds in Plants. A Review. International Journal of Electrochemical Science, 8, 4520-4542. 
[36] Yu, C., Gou, L., Zhou, X., Bao, N. and Gu, H. (2011) Chitosan-Fe $\mathrm{O}_{4}$ Nanocomposite Based Electrochemical Sensors for the Determination of Bisphenol A. Electrochimica Acta, 56, 9056-9063. http://dx.doi.org/10.1016/j.electacta.2011.05.135

[37] Wang, S.F., Tan, Y.M., Zhao, D.M. and Liu, G.D. (2008) Amperometric Tyrosinase Biosensor Based on $\mathrm{Fe}_{3} \mathrm{O}_{4} \mathrm{Nano}^{-}$ particles-Chitosan Nanocomposite. Biosensors and Bioelectronics, 23, 1781-1787. http://dx.doi.org/10.1016/j.bios.2008.02.014

[38] Chang, Y.C. and Chen, D.H. (2005) Preparation and Adsorption Properties of Monodisperse Chitosan- $-\mathrm{Bound}^{\mathrm{Fe}} \mathrm{O}_{4}$ Magnetic Nanoparticles for Removal of Cu(II) Ions. Journal of Colloid and Interface Science, 283, 446-451. http://dx.doi.org/10.1016/j.jcis.2004.09.010

[39] Tapondjou, A.L., Miyamoto, T. and Lacaille-Dubois, M.A. (2006) Glucuronide Triterpene Saponins from Bersama engleriana. Phytochemistry, 67, 2126-2132. http://dx.doi.org/10.1016/j.phytochem.2006.06.034

[40] Habib, I.H.I. (2001) Anodic Stripping Voltammetric Determination of Nitrite Using Carbon Paste Electrode Modified with Chitosan. American Journal of Analytical Chemistry, 2, 284-288. http://dx.doi.org/10.4236/ajac.2011.22035

[41] Brett, A.M.O. and Ghica, M.-E. (2003) Electrochemical Oxidation of Quercetin. Electroanalysis, 15, 1745-1750. http://dx.doi.org/10.1002/elan.200302800

[42] Temerk, Y.M., Ibrahim, H.S.M. and Schuhmann, W. (2006) Cathodic Adsorptive Stripping Voltammetric Determination of the Antitumor Drug Rutin in Pharmaceuticals, Human Urine and Blood Serum. Microchimica Acta, 153, 7-13. http://dx.doi.org/10.1007/s00604-005-0451-3

[43] Lopez, P. and Merkoci, A. (2009) Improvement of the Electrochemical Detection of Catechol by the Use of a Carbon Nanotube Based Biosensor. Analyst, 134, 60-64. http://dx.doi.org/10.1039/b808387h

[44] Nematollahi, D. and Malakzadah, M. (2003) Electrochemical Oxidation of Quercetin in the Presence of Benzenesulfunic Acids. Journal of Electroanalytical Chemistry, 547, 191-195. http://dx.doi.org/10.1016/S0022-0728(03)00188-8

[45] Firuzi, O., Lacanna, A., Petrucci, R., Marrosu, G. and Saso, L. (2005) Evaluation of the Antioxidant Activity of Flavonoids by "Ferric Reducing Antioxidant Power" Assay and Cyclic Voltammetry. Biochimica et Biophysica Acta, 1721, 174-184. http://dx.doi.org/10.1016/j.bbagen.2004.11.001

[46] Gimenes, D.T., dos Santos, W.T.P., Tormin, T.F., Munoz, R.A.A. and Richter, E.M. (2010) Flow-Injection Amperometric Method for Indirect Determination of Dopamine in the Presence of a Large Excess of Ascorbic Acid. Electroanalysis, 22, 74-78. http://dx.doi.org/10.1002/elan.200900331 